\title{
Synthesis of Isoquinolin-4-ols by Palladium-Catalysed Intramolecular Nucleophilic Addition of Aryl Iodides to Aldehydes
}

\author{
Daniel Solé, ${ }^{\mathrm{a}, *}$ Francesco Mariani, ${ }^{\mathrm{a}}$ and Israel Fernández ${ }^{\mathrm{b}, *}$ \\ a Laboratori de Química Orgànica, Facultat de Farmàcia, Universitat de Barcelona, 08028-Barcelona, Spain \\ e-mail: dsole@ub.edu \\ b Departamento de Química Orgánica I, Facultad de Ciencias Químicas, Universidad Complutense, 28040-Madrid, \\ Spain \\ e-mail: israel@quim.ucm.es
}

Received: ((will be filled in by the editorial staff))

Supporting information for this article is available on the WWW under http://dx.doi.org/10.1002/adsc.201\#\#\#\#\#\#.

\begin{abstract}
A palladium-catalysed intramolecular nucleophilic addition of aryl iodides to aldehydes leading to tetrahydroisoquinolin-4-ols is reported. A variety of products were isolated in good to excellent yields. The joint experimental-computational study shows that although two competitive reaction pathways can be promoted by $\operatorname{Pd}(0)$ starting from $\alpha$-(2-iodobenzylamino)-aldehydes, the selectivity of the process can be controlled by the proper selection of the base. While the nucleophilic addition of the aryl-Pd(II) intermediate to the carbonyl group is selectively promoted by using the base $\mathrm{Et}_{3} \mathrm{~N}$, the $\mathrm{C}-\mathrm{H}$ bond activation at the formyl group competes with the nucleophilic addition only when the base is replaced by $\mathrm{Cs}_{2} \mathrm{CO}_{3}$.
\end{abstract}

Keywords: catalysis; palladium; cyclization; nucleophilic addtion; DFT calculations

\section{Introduction}

Aldehydes are probably the most versatile synthon in organic chemistry. Consequently, it is not surprising that, in the last years, several alternative $\mathrm{C}-\mathrm{C}$ bond forming methods have appeared based on the insertion of aldehydes into late transition metalcarbon bonds. ${ }^{[1]}$ Among the variety of available synthetic methodologies, the Pd-catalysed crosscoupling reactions of arylborons and aryl halides with aldehydes have been attracting increasing interest in the last decade. Thus, the intermolecular Pd-catalysed nucleophilic addition of arylborons to aldehydes currently constitutes a powerful methodology for the synthesis of diarylmethanols. ${ }^{[2]}$

In contrast, there are only a few reported examples of the reaction between aryl halides and aldehydes, a transformation that always affords the corresponding acylation product (i.e. arylketone). The intermolecular version of this process requires bimetallic systems ${ }^{[3]}$ or occurs via a Heck-type mechanism by means of $\mathrm{Pd}$-amine cooperative catalysis. ${ }^{[4,5]}$ On the other hand, the intramolecular Pd-catalysed direct acylation of aryl halides with aldehydes, though scarcely explored, has been successfully used for the preparation of benzocyclobutenones $^{[6]}$ and for the synthesis of a variety of azaheterocycles starting from 2iodoanilines. ${ }^{[7]}$

Two mechanistic scenarios (Scheme 1) have been proposed for these intramolecular processes: (1) carbopalladation of the aryl-Pd(II) moiety across the $\mathrm{C}=\mathrm{O}$ bond ${ }^{[8,9,10]}$ followed by $\beta$-hydride elimination would afford the ketone and regenerate the $\operatorname{Pd}(0)$ catalyst (mechanism A), ${ }^{[7]}$ or (2) $\mathrm{C}-\mathrm{H}$ bond activation, loss of HX from the resulting Pd(IV) intermediate, and reductive elimination from the acylPd complex would also form the ketone and regenerate the catalyst (mechanism B). ${ }^{[6 a]}$

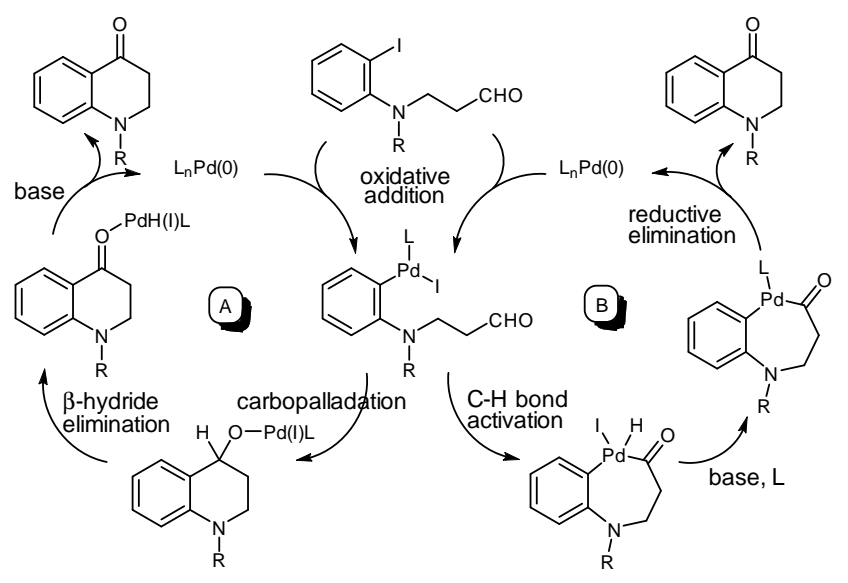

Scheme 1. Proposed catalytic cycles for the intramolecular acylation of aryl halides with aldehydes.

Our DFT calculations have shown that in the reaction of (2-iodoanilino)-aldehydes the carbopalladation of the $\mathrm{C}=\mathrm{O}$ group is kinetically and thermodynamically favoured over the $\mathrm{C}-\mathrm{H}$ bond 
oxidative insertion. This preference may be ascribed to the high nucleophilicity of the carbon atom directly attached to the transition metal because of the $\pi$ donor effect of the ortho-nitrogen atom. ${ }^{[7]}$

Continuing with our interest in these processes, we decided to study the Pd-catalysed reaction of $\alpha-(2-$ iodobenzylamino)-aldehydes (Scheme 2) as a methodology for the synthesis of functionalised tetrahydroisoquinolines, which are important scaffolds present in a number of natural products. ${ }^{[1]}$

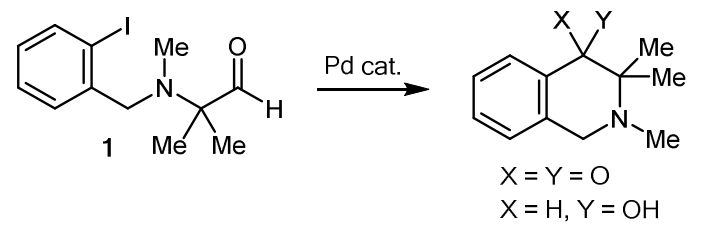

Scheme 2. Synthesis of tetrahydroisoquinolines.

Moreover, the process is not only interesting from a synthetic point of view but also from a mechanistic point of view, because in aldehyde $\mathbf{1}$ the nitrogen atom has been separated from the aryl ring to avoid the delocalisation of its LP into the arylic $\pi$-system.
Thus, we hypothesised that the consequent decrease in the nucleophilicity of the corresponding aryl-Pd(II) intermediate could overcome the nucleophilic attack at the carbonyl group and perhaps favour the $\mathrm{C}-\mathrm{H}$ bond activation pathway commented above.

\section{Results and Discussion}

The reactivity of aldehyde $\mathbf{1}$ with several Pd precatalysts, ligands, and bases was first studied. The most representative results are summarised in Table 1.

The reaction conditions previously employed for the acylation of (2-iodoanilino)-aldehydes ${ }^{[]]}$failed to promote the reaction from (2-iodobenzyl)amine 1 (entries 1-3). Nor was acylation observed under the conditions used for the synthesis of benzocyclobutenones (entry 4) ${ }^{[6 a]}$ Nevertheless, since we observed the formation of small amounts of what seemed to be an aryl-Pd complex when using ( $o$ tolyl $)_{3} \mathrm{P}$ as the ligand (entry 3 ), we decided to modify the reaction conditions by using equimolar amounts of $\operatorname{Pd}(0)$ and ligand, which led to the isolation of complex 2a (45\%) and the ketone $\mathbf{3}$ (10\%) (entry 5).

Table 1. Optimization of the reaction conditions. ${ }^{[a]}$<smiles>CN(Cc1ccccc1I)C(C)(C)C</smiles>

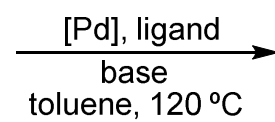

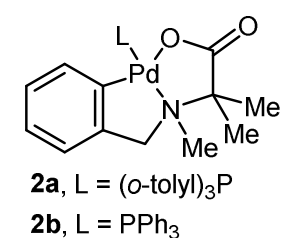

2b, $\mathrm{L}=\mathrm{PPh}_{3}$

2c, $\mathrm{L}=\mathrm{Ph}_{2} \mathrm{P}\left(\mathrm{CH}_{2}\right)_{2} \mathrm{P}(\mathrm{O}) \mathrm{Ph}_{2}$

\begin{tabular}{|c|c|c|c|c|}
\hline Entry & {$[\mathrm{Pd}](\mathrm{mol} \%) /$ Ligand $(\mathrm{mol} \%)$} & Base & Time & Products (Yield [\%]) \\
\hline 1 & $\mathrm{Pd}_{2}(\mathrm{dba})_{3}(5) / \mathrm{dtpf}(10)$ & $\mathrm{Cs}_{2} \mathrm{CO}_{3} / \mathrm{Et}_{3} \mathrm{~N}$ & $24 \mathrm{~h}$ & $1(99 \%)$ \\
\hline 2 & $\mathrm{Pd}_{2}(\mathrm{dba})_{3}(10) /\left({ }^{t} \mathrm{Bu}\right)_{3} \mathrm{PH} \cdot \mathrm{BF}_{4}(20)$ & $\mathrm{Cs}_{2} \mathrm{CO}_{3} / \mathrm{Et}_{3} \mathrm{~N}$ & $24 \mathrm{~h}$ & $1(46 \%)$ \\
\hline 3 & $\mathrm{Pd}_{2}(\mathrm{dba})_{3}(10) /(o \text {-tolyl })_{3} \mathrm{P}(20)$ & $\mathrm{Cs}_{2} \mathrm{CO}_{3} / \mathrm{Et}_{3} \mathrm{~N}$ & $48 \mathrm{~h}$ & 1 (not quantified) ${ }^{[\mathrm{c}]}$ \\
\hline 4 & $\mathrm{Pd}(\mathrm{OAc})_{2}(10) / \mathrm{rac}-\mathrm{BINAP}(15)$ & $\mathrm{Cs}_{2} \mathrm{CO}_{3}$ & $24 \mathrm{~h}^{[\mathrm{d}]}$ & 1 (not quantified) \\
\hline 5 & $\mathrm{Pd}_{2}(\mathrm{dba})_{3}(55) /(o \text {-tolyl })_{3} \mathrm{P}(120)$ & $\mathrm{Cs}_{2} \mathrm{CO}_{3}$ & $24 \mathrm{~h}$ & $\mathbf{2 a}(45 \%), \mathbf{3}(10 \%)$ \\
\hline 6 & $\mathrm{Pd}_{2}(\mathrm{dba})_{3}(10) / \mathrm{PPh}_{3}(25)$ & $\mathrm{Cs}_{2} \mathrm{CO}_{3}$ & $72 \mathrm{~h}$ & $\mathbf{1}$ (not quantified) $^{[\mathrm{e}]}$ \\
\hline 7 & $\mathrm{Pd}_{2}(\mathrm{dba})_{3}(55) / \mathrm{PPh}_{3}(120)$ & $\mathrm{Cs}_{2} \mathrm{CO}_{3}$ & $24 \mathrm{~h}$ & 2b $(27 \%), 3(26 \%), 4(25 \%)$ \\
\hline 8 & $\mathrm{Pd}(\mathrm{OAc})_{2}(20) / \mathrm{dppe}(25)$ & $\mathrm{Cs}_{2} \mathrm{CO}_{3}$ & $72 \mathrm{~h}$ & $\mathbf{1}$ (not quantified) $^{[\mathrm{f}]}$ \\
\hline 9 & $\mathrm{Pd}(\mathrm{OAc})_{2}(100) / \mathrm{dppe}(110)$ & $\mathrm{Cs}_{2} \mathrm{CO}_{3}$ & $15 \mathrm{~h}$ & $\mathbf{1}(10 \%), \mathbf{2 c}(42 \%)^{[\mathrm{g}]}$ \\
\hline 10 & $\mathrm{Pd}_{2}(\mathrm{dba})_{3}(10) / \mathrm{PPh}_{3}(25)$ & $\mathrm{Et}_{3} \mathrm{~N}$ & $72 \mathrm{~h}$ & $4(97 \%)$ \\
\hline 11 & $\mathrm{Pd}\left(\mathrm{PPh}_{3}\right)_{4}(20)$ & $\mathrm{Et}_{3} \mathrm{~N}$ & $72 \mathrm{~h}$ & $4(86 \%)$ \\
\hline 12 & $\mathrm{Pd}(\mathrm{OAc})_{2}(20) / \mathrm{dppe}(25)$ & $\mathrm{Et}_{3} \mathrm{~N}$ & $72 \mathrm{~h}$ & $4(93 \%)$ \\
\hline 13 & $\mathrm{Pd}(\mathrm{OAc})_{2}(20) / \mathrm{rac}-\mathrm{BINAP}(25)$ & $\mathrm{Et}_{3} \mathrm{~N}$ & $48 \mathrm{~h}$ & $4(76 \%)$ \\
\hline 14 & $\mathrm{Pd}_{2}(\mathrm{dba})_{3}(5) / \mathrm{PPh}_{3}(11)$ & $\mathrm{Et}_{3} \mathrm{~N}$ & $24 \mathrm{~h}$ & $4(83 \%)$ \\
\hline
\end{tabular}

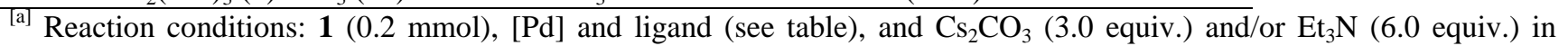
toluene at $120^{\circ} \mathrm{C}$ in a sealed tube.

${ }^{[b]}$ Isolated yield.

${ }^{[c]}$ Minor amounts of $\mathbf{2 a}$ were observed in the reaction mixture.

${ }^{[\mathrm{d}]}$ Either THF or toluene was used as the solvent.

${ }^{[e]}$ Minor amounts of $\mathbf{2 b}$ and $\mathbf{3} \approx 10 \%, 2: 1$ ratio) were observed in the reaction mixture.

${ }^{[\mathrm{ff}]}$ Minor amounts of $\mathbf{2 c}$ were observed in the reaction mixture.

${ }^{[\mathrm{g}]}$ Minor amounts of $\mathbf{3}$ and $\mathbf{4}(\approx 5 \%, 1: 1$ ratio) were observed in the reaction mixture.

Similar behaviour was observed when $\mathrm{PPh}_{3}$ and dppe were used as the ligand. Thus, the use of catalytic amounts of a Pd source and ligand resulted mainly in the recovery of the aldehyde and the formation of minor amounts of the corresponding Pd complexes $\mathbf{2 b}$ (entry 6) and $\mathbf{2 c}$ (entry 8 ). On the other 
hand, equimolar amounts of both $\mathrm{Pd}$ and $\mathrm{PPh}_{3}$ led to complex 2b (27\%), ketone 3 (26\%), and alcohol 4 (25\%) (entry 7), while the use of equimolar amounts of Pd and dppe resulted mainly in the formation of the Pd complex 2c (42\%) (entry 9).

The structures of complexes 2a-c were unambiguously assigned from their spectroscopic data. ${ }^{[12]}$ Moreover, tridentate [C,N,O] Pd(II) complex 2b was prepared independently starting from the corresponding methyl ester (Scheme 3). ${ }^{[13]}$

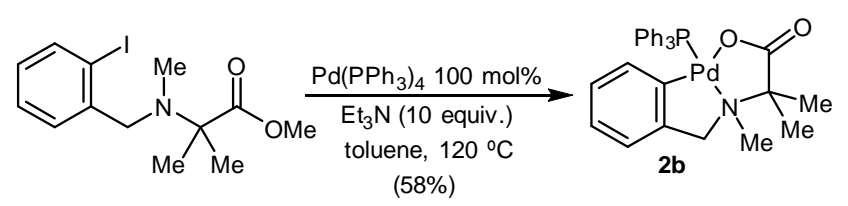

Scheme 3. Alternative synthesis of tridentate $[\mathrm{C}, \mathrm{N}, \mathrm{O}]$ Pd(II) complex $\mathbf{2 b}$.

Density Functional Theory (DFT) calculations were carried out at the PCM-B3LYP/def2TZVP//B3LYP/def2-SVP level ${ }^{[14]}$ to gain more insight into the mechanism of the above Pd-promoted reactions of $\mathbf{1}$, which led to the completely unexpected formation of $\mathrm{Pd}$ complexes 2a-c. The computed reaction profile starting from intermediate INT0, readily formed from the initial oxidative addition of $\mathbf{1}$ upon iodide ligand exchange by the $\mathrm{CO}_{3}^{-2}$, is showed in Figure 1, which gathers the corresponding computed free energies $\left(\Delta \mathrm{G}_{393}\right.$, at $393.15 \mathrm{~K}$ ) in toluene as solvent.
All our attempts to locate a transition state associated with the direct $\mathrm{C}-\mathrm{H}$ activation reaction leading to a $\mathrm{Pd}(\mathrm{IV})$ intermediate similar to that depicted in Scheme 1 met with no success. Fortunately, we found an alternative concerted metalation-deprotonation (CMD) process which is mediated by $\mathrm{CO}_{3}^{-2}$ (Figure 1). Thus, intermediate INT0 evolves to INT1 by initial loss of $\mathrm{PPh}_{3}$. Intramolecular saturation of its coordination vacant by the nitrogen atom lone-pair occurs then to produce INT2 via transition state TS-N in a highly exergonic transformation $\left(\Delta \mathrm{G}_{393}=-20.3 \mathrm{kcal} / \mathrm{mol}\right)$. This species is transformed into the Pd(II) intermediate INT3 via the transition state TS1. This saddle point is associated with the concerted hydrogen migration from the aldehyde to the carbonate ligand and $\mathrm{Pd}-\mathrm{C}(=\mathrm{O})$ bond formation. In this sense, this process is analogous to the palladium-catalysed $\mathrm{C}-\mathrm{H}$ arylation reactions which is assisted by acetate ${ }^{[15]}$ or carbonate. ${ }^{[16]}$ Indeed, the computed activation barrier for this process $\left(\Delta \mathrm{G}^{\ddagger}=38.1 \mathrm{kcal} / \mathrm{mol}\right.$, at $\left.120^{\circ} \mathrm{C}\right)$ is also similar to that found for AcO-assisted CMD arylation reactions. ${ }^{[15]}$ Then, INT3 is transformed into INT4 by releasing of the $\mathrm{HCO}_{3}^{-}$ligand and coordination of $\mathrm{PPh}_{3}$ in an exergonic process $\left(\Delta \mathrm{G}_{393}\right.$ $=-7.3 \mathrm{kcal} / \mathrm{mol}$ ). Species INT4 is finally converted into the observed complex $\mathbf{2 b}$ very likely via reaction with $\mathrm{O}_{2}$ leading to the peroxo-complex INT5, as previously described in the literature for related acylpalladium systems. ${ }^{[17]}$ Alternatively, INT4 can produce ketone $\mathbf{3}$ via TS2, a saddle point associated with the reductive elimination forming the new $\mathrm{C}(\operatorname{aryl})-\mathrm{C}(=\mathrm{O})$ bond.

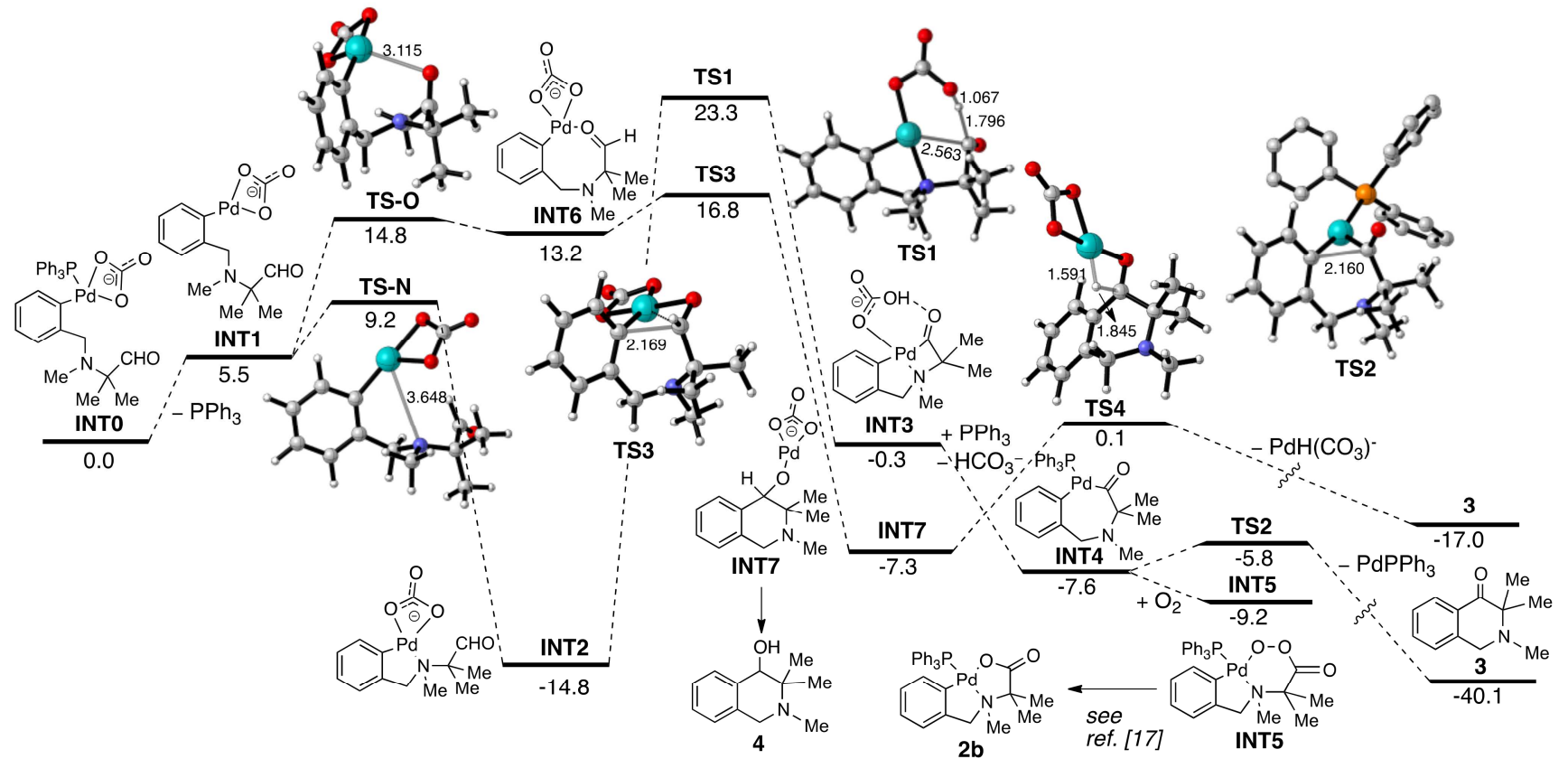

Figure 1. Computed reaction profile starting from INT0. Free energy values $\left(\Delta \mathrm{G}_{393}\right.$, computed at $\left.120{ }^{\circ} \mathrm{C}\right)$ and bond distances are given in $\mathrm{kcal} / \mathrm{mol}$ and angstroms, respectively. All data have been computed at the PCM(toluene)B3LYP/def2-TZVP//B3LYP/def2-SVP level.

In addition, ketone $\mathbf{3}$ and alcohol $\mathbf{4}$ can be also produced from an alternative reaction pathway starting from the same intermediate INT1. Indeed, our calculations indicate that this species can be 
converted into INT6 via TS-O, a transition state associated with the intramolecular coordination of the carbonyl oxygen atom. This process is endergonic and proceeds with a higher activation barrier than the analogous process involving TS-N $\left(\Delta \Delta \mathrm{G}^{\ddagger}=5.6\right.$ $\mathrm{kcal} / \mathrm{mol}$ ). Despite that, the formed INT6 readily evolves to INT7 in a highly exergonic nucleophilic addition reaction $\left(\Delta \mathrm{G}_{393}=-20.5 \mathrm{kcal} / \mathrm{mol}\right)$ with a very low activation barrier of only $3.6 \mathrm{kcal} / \mathrm{mol}$. Therefore, although the formation of INT2 is kinetically and thermodynamically favoured over INT6, the high barrier of the process involving TS1 makes the pathway involving TS3 competitive. From INT7, ketone $\mathbf{3}$ is formed through a $\beta$-hydride elimination reaction via TS4 (computed barrier of $7.4 \mathrm{kcal} / \mathrm{mol}$ ), whereas alcohol $\mathbf{4}$ is alternatively produced in a Cs(I)-assisted reaction. ${ }^{[18]}$

The above computational data show that, although ketone 3 could be derived from both reaction pathways, the formation of complexes 2a-c can only be explained by a bias towards the $\mathrm{C}-\mathrm{H}$ bond activation process. The formation of the quite stable $\mathrm{Pd}$ complexes 2, which is due to the adventitious presence of $\mathrm{O}_{2}$ in the reaction mixture, ${ }^{[19]}$ would divert the metal from the productive cycle leading to ketone 3, thus explaining why the acylation reaction is not really catalytic when using $\mathrm{Cs}_{2} \mathrm{CO}_{3}$ as the base.

Moreover, the above computational data also suggest that the $\mathrm{C}-\mathrm{H}$ activation process needs $\mathrm{CO}_{3}^{-2}$ to take place. Therefore, in the absence of $\mathrm{Cs}_{2} \mathrm{CO}_{3}$, the reaction pathway should switch from $\mathrm{C}-\mathrm{H}$ activation to nucleophilic addition, allowing us to develop a catalytic coupling process. Indeed, to our delight, this is exactly what occurred when the base $\mathrm{Cs}_{2} \mathrm{CO}_{3}$ was changed to $\mathrm{Et}_{3} \mathrm{~N}$. Thus, when 1 was treated with a catalytic amount of $\mathrm{Pd}_{2}(\mathrm{dba})_{3}$ and $\mathrm{PPh}_{3}$, in the presence of $\mathrm{Et}_{3} \mathrm{~N}$, tetrahydroisoquinolin-4-ol 4 was isolated in $97 \%$ yield (entry 10, Table 1). Similar results were obtained when using either $\mathrm{Pd}\left(\mathrm{PPh}_{3}\right)_{4}$, $\mathrm{Pd}(\mathrm{OAc})_{2} / \mathrm{dppe}$ or $\mathrm{Pd}(\mathrm{OAc})_{2} / \mathrm{rac}-\mathrm{BINAP}$ as the catalyst (entries 11-13). Both the amount of catalyst and reaction time were successfully reduced (entry 14).

As proposed above, our DFT calculations confirm that the formation of alcohol $\mathbf{4}$ in the presence of $\mathrm{Et}_{3} \mathrm{~N}$ also derives from a nucleophilic addition reaction (Figure 2). Thus, intermediate INT6-I, formed through the initial oxidative addition step and subsequent coordination of the carbonyl group, evolves to INT7-I via TS3-I, a transition state analogous to TS3, with a computed activation barrier of $\Delta \mathrm{G}^{\ddagger}=16.6 \mathrm{kcal} / \mathrm{mol}$ in a highly exergonic transformation $\left(\Delta \mathrm{G}_{393}=-15.1 \mathrm{kcal} / \mathrm{mol}\right)$. As clearly seen in Figure 2, the coordination of the nitrogen atom to the transition metal in INT7-I hinders the cisoid conformation essential to $\beta$-hydride elimination, ${ }^{[20]}$ which explains the non-formation of ketone 3. As a consequence, INT7-I exclusively evolves to alcohol 4 via a $\mathrm{Et}_{3} \mathrm{~N}$-mediated reductive protonation process through INT8. ${ }^{[8,21]}$

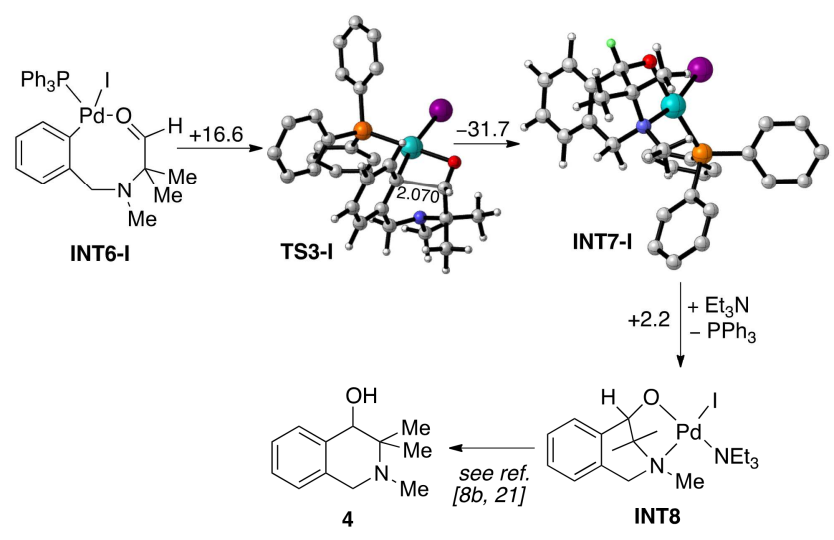

Figure 2. Computed nucleophilic addition reaction. Energy values are given in $\mathrm{kcal} / \mathrm{mol}$. See Figure 1 for additional caption details.

As shown, the results obtained during the optimisation studies with aldehyde 1 (Table 1) and the DFT calculations clearly indicate a competition between the nucleophilic addition and the $\mathrm{C}-\mathrm{H}$ bond activation processes in the $\mathrm{Pd}$-mediated reactions when using $\mathrm{Cs}_{2} \mathrm{CO}_{3}$ as the base. In order to check the effect of the aromatic ring substituents on the balance between both processes, the Pd-promoted reactions of aldehydes $\mathbf{5 a}, \mathbf{b}$ in the presence of $\mathrm{Cs}_{2} \mathrm{CO}_{3}$ were also explored (Table 2).

Table 2. Reactions of aldehydes $\mathbf{5 a - b}$ using $\mathrm{Cs}_{2} \mathrm{CO}_{3}$ as the base. $^{[a]}$

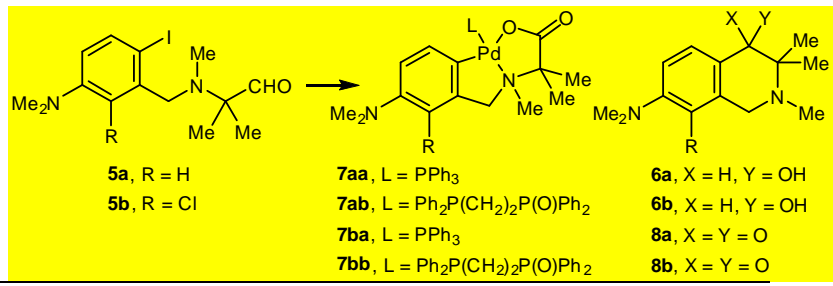

\begin{tabular}{|c|c|c|c|}
\hline Entry & Aldehyde & $\begin{array}{l}{[\mathrm{Pd}](\mathrm{mol} \%) /} \\
\text { Ligand }(\mathrm{mol} \%)\end{array}$ & $\begin{array}{l}\text { Products } \\
(\text { Yield [\%]) }\end{array}$ \\
\hline 1 & $5 a$ & $\begin{array}{l}\mathrm{Pd}_{2}(\mathrm{dba})_{3}(55) / \\
\mathrm{PPh}_{3}(120)\end{array}$ & $\begin{array}{l}\text { 6a }(19 \%) \\
7 \mathbf{a a}(12 \%) \\
8 \mathbf{a}(24 \%)\end{array}$ \\
\hline 2 & $5 a$ & $\begin{array}{l}\mathrm{Pd}(\mathrm{OAc})_{2}(100) / \\
\text { dppe }(100)\end{array}$ & $\begin{array}{l}\text { 6a }(33 \%) \\
7 \mathbf{a b}(26 \%) \\
8 \mathbf{a}(30 \%)\end{array}$ \\
\hline 3 & $5 \mathbf{b}$ & $\begin{array}{l}\mathrm{Pd}_{2}(\mathrm{dba})_{3}(55) / \\
\mathrm{PPh}_{3}(120)^{[\mathrm{cc}]}\end{array}$ & $\begin{array}{l}7 \mathbf{b a}(32 \%) \\
\mathbf{6 b}(10 \%) \\
\mathbf{8 b}(35 \%)\end{array}$ \\
\hline 4 & $5 b$ & $\begin{array}{l}\mathrm{Pd}(\mathrm{OAc})_{2}(100) / \\
\text { dppe }(100)\end{array}$ & $\begin{array}{l}7 \mathbf{b b}(47 \%) \\
\mathbf{8 b}(9 \%)\end{array}$ \\
\hline
\end{tabular}

${ }^{\text {[a] }}$ Reaction conditions: $5(0.2 \mathrm{mmol}),[\mathrm{Pd}]$ and ligand (see table), and $\mathrm{Cs}_{2} \mathrm{CO}_{3}$ (3.0 equiv.) in toluene at $120{ }^{\circ} \mathrm{C}$ in a sealed tube for $15 \mathrm{~h}$.

${ }^{[b]}$ Isolated yield.

[c] $24 \mathrm{~h}$.

When starting from 5a, which bears a strong electron-donating dimethylamino group on the 
aromatic ring, an increase in the nucleophilic addition alcohol-to-Pd-complex ratio was observed (compare entries 7 and 9 of Table 1 with entries 1 and 2 of Table 2 , respectively). Interestingly, the $\pi$-donor effect of the dimethylamino group was almost completely neutralised by the introduction of an additional $\mathrm{Cl}$ substituent at the aryl group. Thus, the use of $\mathrm{PPh}_{3}$ as the ligand (entry 3, table 2) gave an alcohol-to-Pd-complex ratio similar to that obtained when starting from 1 under similar conditions. On the other hand, when starting from aldehyde $\mathbf{5 b}$ and using dppe as the ligand, the formation of the Pd-complex became, once again, the predominant reaction pathway (entry 4 , table 2 ).

These results confirm that the nucleophilic addition is strongly related to the electron density on the $\mathrm{C}$ (aryl) atom, as suggested previously by us. ${ }^{\text {[7] }}$ Indeed, the lower nucleophilicity of this carbon atom in INT6 (measured by the corresponding NBOcharge of $q=-0.176)$ compared to the analogous Pdintermediate derived from a 2-iodoaniline $(q=-$ $0.245)^{[10 \mathrm{a}]}$ would also explain why the competition between $\mathrm{C}-\mathrm{H}$ bond activation and nucleophilic addition is observed in (2-iodobenzylamino)aldehydes but not in (2-iodoanilino)-aldehydes. ${ }^{\text {[7a] }}$

Finally, with the optimised conditions for the intramolecular Pd-catalysed nucleophilic addition in hand, we examined the scope of the reaction for the synthesis of diversely functionalised tetrahydroisoquinolin-4-ols (Table 3).

Table 3. Synthesis of tetrahydroisoquinolin-4-ols. ${ }^{\text {a] }}$

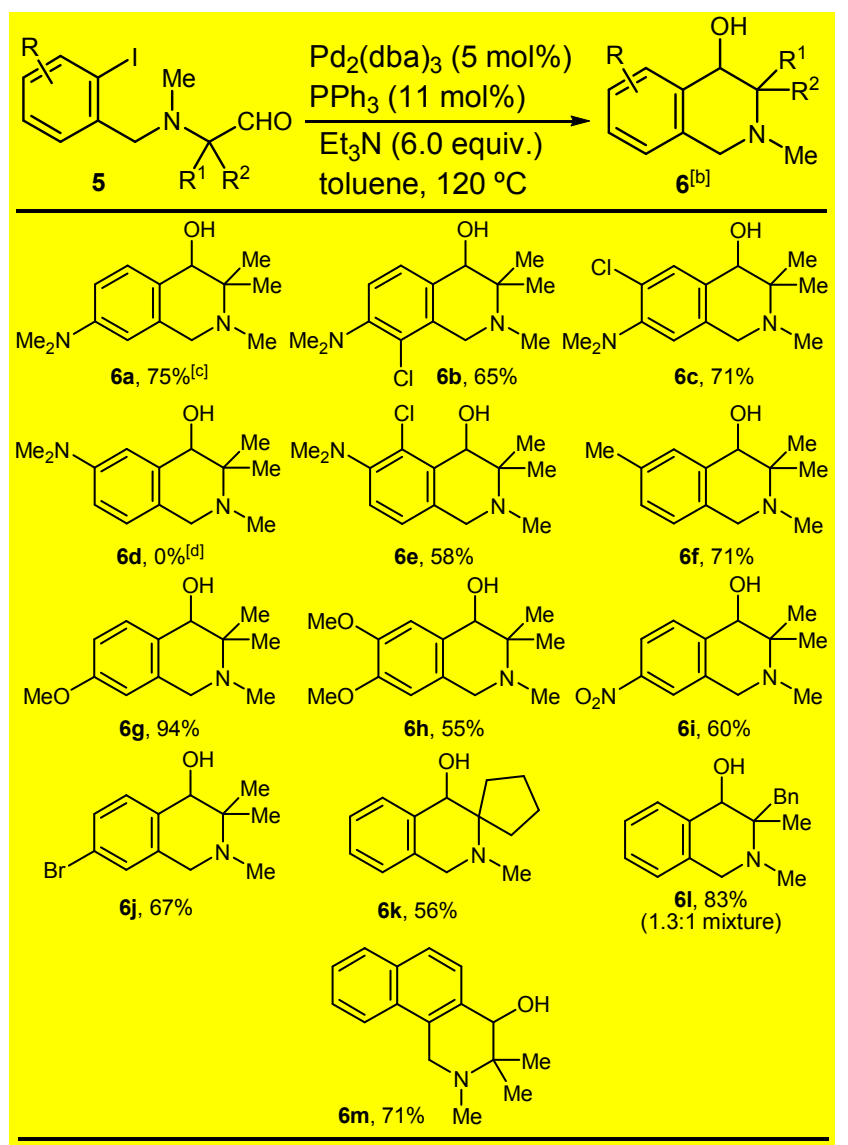

[a] Reaction conditions: 5 (0.2 mmol), $\mathrm{Pd}_{2}(\mathrm{dba})_{3}(5 \mathrm{~mol} \%)$, $\mathrm{PPh}_{3}(11 \mathrm{~mol} \%)$, and $\mathrm{Et}_{3} \mathrm{~N}$ (6.0 equiv.) in toluene at $120^{\circ} \mathrm{C}$ in a sealed tube for $24 \mathrm{~h}$.

${ }^{[b]}$ Isolated yield.

[c] 6a (73\%) and 5a (20\%) were obtained when using $\mathrm{Pd}(\mathrm{OAc})_{2}(20 \mathrm{~mol} \%)$ and dppe $(25 \mathrm{~mol} \%)$ as the catalyst. [d] 4-[(N,N-Diethylamino)methyl]- $N, N$-dimethylaniline was isolated from the reaction mixture $(24 \%)$.

The examples presented in Table 3 demonstrate the generality and functional group tolerance of the reaction. Overall, the introduction of substituents on the aromatic ring had little effect on the success of the reaction. Thus, aldehydes bearing electrondonating or electron-withdrawing groups, as well as a combination of both, on the aromatic ring afforded the corresponding nucleophilic addition alcohols in good yields. It is important to note that the failure to prepare 6d was mainly a consequence of the instability of the 4-( $N, N$-dimethylamino)benzylamino moiety at the starting aldehyde, which underwent fragmentation under the reaction conditions. On the other hand, the bromo-substituted aldehyde $\mathbf{5 j}$ selectively underwent the cyclisation reaction to give 6j, which would allow further synthetic transformations by transition metal-catalysed coupling reactions. Spirocyclic and naphtho-fused heterocycles were also smoothly prepared.

In summary, we have developed an efficient protocol for the synthesis of tetrahydroisoquinolin-4ols by means of the Pd-catalysed intramolecular nucleophilic addition of aryl halides to aldehydes. The use of $\mathrm{Et}_{3} \mathrm{~N}$ as the base was found to be essential for the formation of isoquinolin-4-ols. In contrast, competition between a $\mathrm{CO}_{3}^{-2}$-mediated concerted metalation-deprotonation process and nucleophilic addition to the carbonyl group was observed when using the base $\mathrm{Cs}_{2} \mathrm{CO}_{3}$, which generated mixtures of the acylation product (i.e. tetrahydroisoquinolin-4one) and stable tridentate [C,N,O] $\mathrm{Pd}$ (II) complexes. The outcome of these reactions provides new insight into the nucleophilic addition versus $\mathrm{C}-\mathrm{H}$ bond activation dichotomy in $\mathrm{Pd}$-catalysed reactions of amino-tethered aryl iodides and aldehydes. Further exploration to expand the scope of the nucleophilic addition reaction to other heterocyclic systems, as well as to develop an enantioselective process, is underway in our laboratories and will be reported in due course.

\section{Experimental Section}

\section{Typical Procedure for the Pd(0)-Catalysed Reactions (Table 1, Entry 10)}

A mixture of aldehyde 1 (70 mg, $0.22 \mathrm{mmol}), \mathrm{Et}_{3} \mathrm{~N}(0.18$ $\mathrm{mL}, 1.32 \mathrm{mmol}), \mathrm{Pd}_{2}(\mathrm{dba})_{3}(20 \mathrm{mg}, 0.022 \mathrm{mmol})$, and $\mathrm{PPh}_{3}$ $(14.5 \mathrm{mg}, 0.055 \mathrm{mmol})$ in toluene $(8 \mathrm{~mL})$ was stirred at $120^{\circ} \mathrm{C}$ in a sealed tube for $72 \mathrm{~h}$. The reaction mixture was partitioned between saturated $\mathrm{NaHCO}_{3}$ aqueous solution and $\mathrm{Et}_{2} \mathrm{O}$. The organic extracts were washed with brine, dried, and concentrated. The residue was purified by 
chromatography (from $\mathrm{CH}_{2} \mathrm{Cl}_{2}$ to $\mathrm{CH}_{2} \mathrm{Cl}_{2}-\mathrm{MeOH} 8 \%$ ) to give 4 (41 mg, 97\%).

\section{Supporting Information}

Detailed experimental data, characterization and copies of NMR-spectra of new compounds, and computational details.

\section{Acknowledgements}

We gratefully acknowledge financial support for this work from the MINECO (CTQ2012-31391, CTQ2010-20714-C02-01/BQU, CSD2007-0006) and from the CAM (P2009/PPQ1634AVANCAT).

\section{References}

[1] See, for example: a) M. Pucheault, S. Darses, J.-P. Genet, J. Am. Chem. Soc. 2004, 126, 15356; b) N. Imlinger, M. Mayr, D. Wang, K. Wurst, M. R. Buchmeiser, Adv. Synth. Catal. 2004, 346, 1836; c) P. Shukla, C. H. Cheng, Org. Lett. 2006, 8, 2867; d) O. Chuzel, A. Roesch, J.-P. Genet, S. Darses, J. Org. Chem. 2008, 73, 7800; e) Y.-H. Liao, Q.-S. Hu, J. Org. Chem. 2010, 75, 6986; f) H. Li, Y. Xu, E. Shi, W. Wei, X. Suo, X. Wan, Chem. Commun. 2011, 7880; g) J. Karthikeyan, K. Parthasarathy, C.-H. Cheng, Chem. Commun. 2011, 10461; h) H. Zheng, J. Ding, J. Chen, M. Liu, W. Gao, H. Wu, Synlett 2011, 1626.

[2] a) T. Yamamoto, T. Ohta, Y. Ito, Org. Lett. 2005, 7, 4153; b) K. Suzuki, T. Arao, S. Ishii, Y. Maeda, K. Kondo, T. Aoyama, Tetrahedron Lett. 2006, 47, 5789; c) P. He, Y. Lu, C.-G. Dong, Q.-S. Hu, Org. Lett. 2007, 9, 343; d) A. Novodomskà, M. Dudicovà, F. R. Leroux, F. Colobert, Tetrahedron: Asymmetry 2007, 18, 1628; e) S. Lin, X. Lu, J. Org. Chem. 2007, 72, 9757; f) M. Kuriyama, R. Shimazawa, R. Shirai, J. Org. Chem. 2008, 73, 1597; g) I. N. Francesco, A. Wagner, F. Colobert, Eur. J. Org. Chem. 2008, 5692; h) C. Qin, J. Chen, H. Wu, J. Cheng, Q. Zhang, B. Zuo, W. Su, J. Ding, Tetrahedron Lett. 2008, 49, 1884; i) R. Zhang, Q. $\mathrm{Xu}, \mathrm{X}$. Zhang, T. Zhang, M. Shi, Tetrahedron: Asymmetry 2010, 21, 1928; j) Y.-X. Liao, C.-H. Xing, M. Israel, Q.-S. Hu, Tetrahedron Lett. 2011, 52, 3324; k) F. Luo, S. Pan, C. Pan, P. Qian, J. Cheng, Adv. Synth. Catal. 2011, 353, 320; 1) see also: Z. Ye, G. Lv, W. Wang, M. Zhang, J. Cheng, Angew. Chem. 2010, 122, 3753; Angew. Chem. Int. Ed. 2010, 49, 3671.

[3] a) Y.-C. Huang, K.-K. Majumdar, C.-H. Cheng, J. Org. Chem. 2002, 67, 1682; b) S. Ko, B. Kang, S. Chang, Angew. Chem. 2005, 117, 459; Angew. Chem. Int. Ed. 2005, 44,455 .

[4] a) J. Ruan, O. Saidi, J. A. Iggo, J. Xiao, J. Am. Chem. Soc. 2008, 130, 10510; b) P. Colbon, J. Ruan, M. Purdie, J. Xiao, Org. Lett. 2010, 12, 3670; c) L. Adak, S Bhadra, B. C. Ranu, Tetrahedron Lett. 2010, 51, 3811; d) P. Colbon, J. Ruan, M. Purdie, K. Mulholland, J. Xiao, Org. Lett. 2011, 13, 5456.

[5] The direct Pd-catalysed intermolecular acylation of aryl bromides with aldehydes has been recently reported, see: P. Nareddy, C. Mazet, Chem. Asian J. 2013, 8, 2579 .

[6] a) P. Álvarez-Bercedo, A. Flores-Gaspar, A. Correa, R. Martin, J. Am. Chem. Soc. 2010, 132, 466; b) A. Flores-Gaspar, A. Gutiérrez-Bonet, R. Martin, Org. Lett. 2012, 14, 5234.

[7] a) D. Solé, F. Mariani, I. Fernández, M. A. Sierra, J. Org. Chem. 2012, 77, 10272; b) D. Solé, F. Mariani, J. Org. Chem. 2013, 78, 8136; see also: c) D. Solé, I. Fernández, Acc. Chem. Res. 2014, 47, 168.

[8]For the addition to ketone carbonyls, see: a) L. G. Quan, M. Lamrani, Y. Yamamoto, J. Am. Chem. Soc. 2000, 122, 4827; b) D. Solé, L. Vallverdú, X. Solans, M. Font-Bardia, J. Bonjoch, J. Am. Chem. Soc. 2003, 125, 1587; c) G. Liu, X. Lu, J. Am. Chem. Soc. 2006, 128, 16504; d) Y.-X. Jia, D. Katayev, E. P. Kündig, Chem. Commun. 2010, 130; e) L. Yin, M. Kanai, M. Shibasaki, Angew. Chem. 2011, 123, 7762; Angew. Chem. Int. Ed. 2011, 50, 7620 .

[9] For the addition to ester and amide carbonyls see: a) D. Solé, O. Serrano, Angew. Chem. 2007, 119, 7408; Angew. Chem. Int. Ed. 2007, 46, 7270; b) D. Solé, O. Serrano, J. Org. Chem. 2008, 73, 9372.

[10] a) I. Fernández, D. Solé, M. A. Sierra, J. Org. Chem. 2011, 76, 1592; b) D. Solé, I. Fernández, M. A. Sierra, Chem. Eur. J. 2012, 18, 6950.

[11] For recent reviews, see: a) K. Bhadra, G. S. Kumar, Mini-Reviews in Medicinal Chemistry 2010, 10, 1235; b) A. L. Souto, J. F. Tavares, M. Sobral da Silva, M. F. F. M. Diniz, P. Filgueiras de Athayde-Filho, J. M. Barbosa-Filho, Molecules 2011, 16, 8515; c) P. E. Alford, Progress in Heterocyclic Chemistry 2011, 23, 329.

[12] For related complexes, see: D. Solé, S. Díaz, X. Solans, M. Font-Bardia, Organometallics 2006, 25, 1995.

[13] The formation of palladacyclic carboxylate complexes from esters has been proposed in some Pdcatalysed reactions. See, for example: R. C. Larock, X. Han, M. J. Doty, Tetrahedron Lett. 1998, 39, 5713.

[14] See computational details in the Supplementary Information.

[15] a) D. Balcells, E. Clot, O. Eisenstein, Chem. Rev. 2010, 110, 749; b) S. I. Gorelsky, Coord. Chem. Rev. 2013, 257, 153; c) For a recent example, see: P. Ricci, K. Krämer, X. C. Cambeiro, I. Larrosa, J. Am. Chem. Soc. 2013, 135, 13258.

[16] See, for instance: a) M. Chaumontet, R. Piccardi, N. Audic, J. Hitce, J.-L. Peglion, E. Clot, O. Baudoin, J. Am. Chem. Soc. 2008, 130, 15157; b) S. Rousseaux, M. Davi, J. Sofack-Kreutzer, C. Pierre, C. E. Kefalidis, E. Clot, K. Fagnou, O. Baudoin, J. Am. Chem. Soc. 2010, 132, 10706; c) L. Ackermann, Chem. Rev. 2011, 111, 1315.

[17] a) J. Vicente, J.-A. Abad, A. D. Frankland, M. C. Ramírez de Arellano, Chem. Eur. J. 1999, 5, 3066; b) 
D. Solé, L. Vallverdú, X. Solans, M. Font-Bardia, Chem. Comm. 2005, 2738; c) D. Solé, X. Solans, M. Font-Bardia, Dalton Trans. 2007, 4286.

[18] A similar process has been proposed for the addition reactions to ketones, see references $7 \mathrm{a}-\mathrm{b}, \mathrm{d}$.

[19] Although we were not able to avoid the formation of the Pd complexes 2, small variations on the ketone to complex ratio were obtained in degassed reaction mixtures.
[20] A similar behaviour was found in related $\sigma$ alkylpalladium Heck intermediates. See: E. M. Beccalli, G. Broggini, M. Martinelli, N. Masciocchi, S. Sottocornola, Org. Lett. 2006, 8, 4521.

[21] C. C. Lu, J. C. Peters, J. Am. Chem. Soc. 2004, 126, 15818. 


\section{UPDATE}

Synthesis of Isoquinolin-4-ols by Palladium-

Catalysed Intramolecular Nucleophilic Addition of Aryl Iodides to Aldehydes

Adv. Synth. Catal. Year, Volume, Page - Page

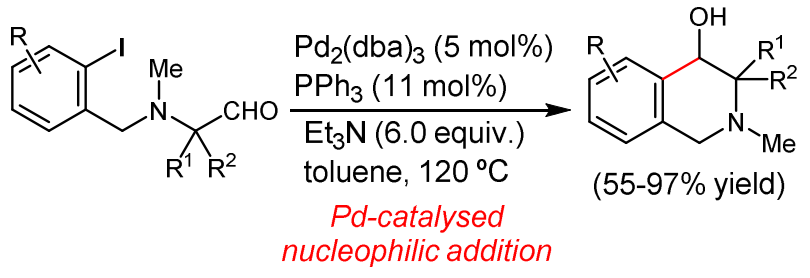

Daniel Solé,* Francesco Mariani, and Israel nucleophilic addition

Fernández* 